
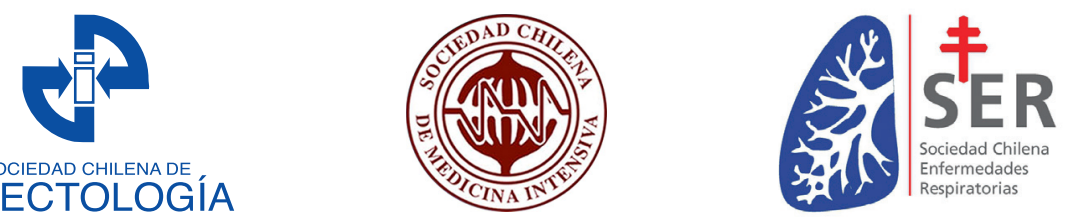

\title{
Consideraciones Farmacológicas para el manejo de SARS-CoV-2 (COVID-19). Primera versión
}

\author{
RUTH ROSALES C. QF*, CLAUDIO GONZÁLEZ M. QF** y FERNANDO BERNAL O. QF***
}

Pharmacological considerations for the management of SARS-CoV-2 (COVID-19). $1^{\text {st }}$ version

\section{Tratamiento}

No existe actualmente evidencia científica robusta procedente de ensayos clínicos randomizados para recomendar un tratamiento especifico para COVID-19 en pacientes con sospecha o confirmación de COVID-19. Sin embargo, con los conocimientos actuales, basados en reportes de casos, estudios observacionales y recomendación de expertos se pueden hacer recomendaciones de tratamientos que se detallan en este documento.

Es relevante informar a la autoridad sanitaria todo evento adverso que sea pesquisado durante o posterior al tratamiento.

\section{Simbología tabla}

* No utilizar sondas de poliuretano, formulación contiene un alto contenido de alcohol (40\%), preferir sondas silicona o PVC.

¥ Priorizar formulación cuando la VO no se encuentre fácilmente disponible.

$\forall$ Sólo si Lopinavir/rit no se encuentre fácilmente disponible.

$\leftrightarrow$ Usar con precaución en pacientes con enfermedad cardíaca, antecedentes de arritmias ventriculares, hipokalemia y/o hipomagnesemia no corregida, o bradicardia (menos de $50 \mathrm{lpm}$ ), y durante la administración concomitante con agentes prolongadores del intervalo QT debido al potencial sinérgico.

¥ Usar con precaución en pacientes con déficit de glucosa 6-fosfato deshidrogenasa.

$£$ Medicamento experimental no disponible en Chile hasta el momento. En otros países el laboratorio lo ofrece como tratamiento compasivo.

$\Delta$ No utilizar con QTc $>500 \mathrm{msec}$ o aumento $>25 \%$ del basal, Miastenia Gravis o Porfiria.

$\Varangle$ Comprimido debe ser triturado completamente y disuelto en $20 \mathrm{~mL}$ en SF (suero fisiológico) $0,9 \%$ para administrar por sonda naso-gástrica. Considere formulación magistral.

$\nabla$ No iniciar tratamiento en pacientes con infecciones activas. Interrumpir la administración si el paciente desarrolla una infección grave, hasta que la infección esté controlada.

2 Muy poco respaldo de uso en pacientes de edad menor a 2 años.

$\infty$ Cerca del $60 \%$ de la dosis oral de cloroquina o de hidroxicloroquina son eliminadas por vía urinaria, alrededor del $10 \%$ por vía fecal y el $30 \%$ restante por vía cutánea. Por vía urinaria, la hidroxicloroquina es excretada en un $13 \%$ como metabolitos y en un $87 \%$ no metabolizada.

* Unidad de Paciente Crítico. Hospital Barros Luco Trudeau. Santiago, Chile.

** Calidad y seguridad del paciente. Hospital Dr. Exequiel González Cortés. Santiago, Chile.

*** Infectología. Hospital San Juan de Dios. Santiago, Chile. 


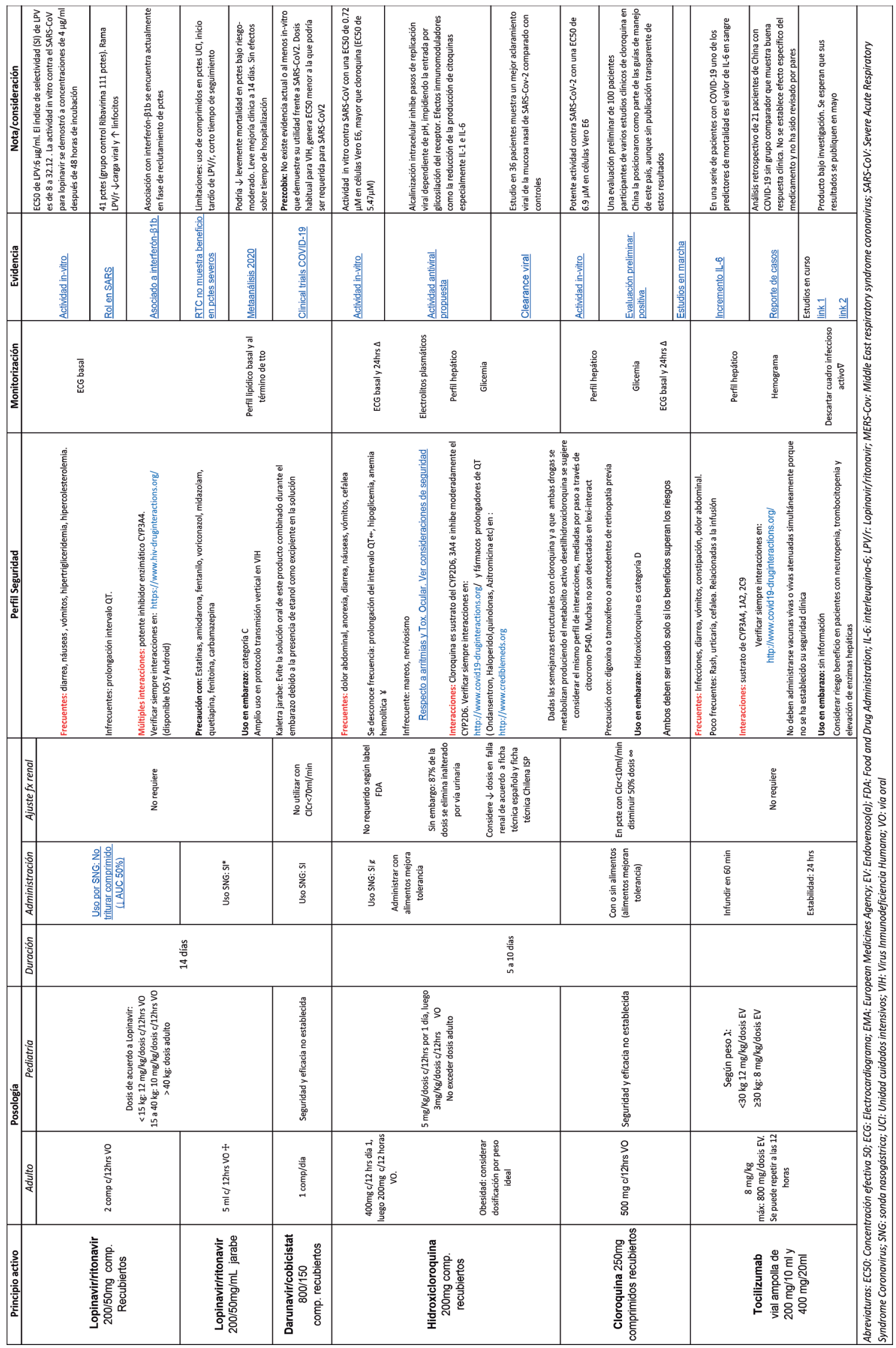




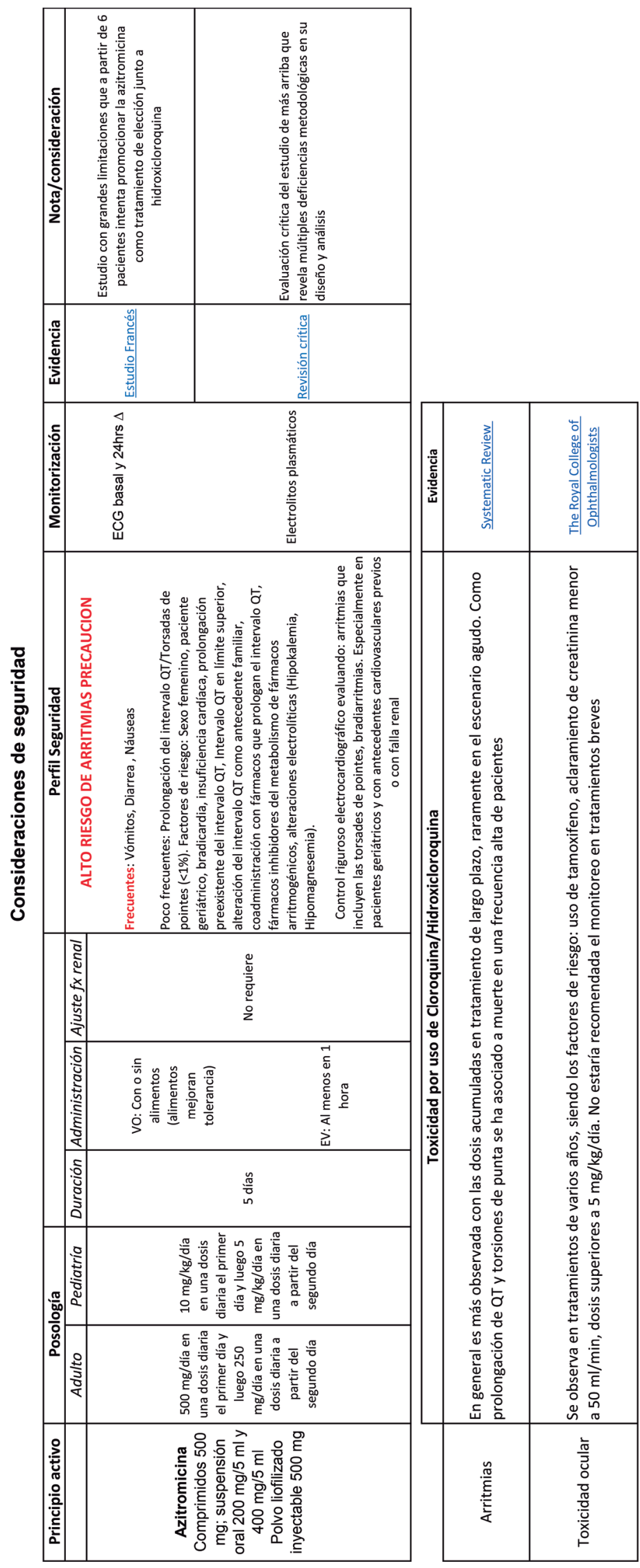

Correspondencia a: QF. Fernando Bernal Ortiz Unidad Infectología

Hospital San Juan de Dios Santiago. Chile

Email: fernando.bortiz@gmail.com 